\title{
Advancing quantitative techniques to improve understanding of the skeletal structure-function relationship
}

\author{
Frances T. Sheehan ${ }^{1 *}$, Elizabeth L. Brainerd ${ }^{2}$, Karen L. Troy ${ }^{3}$, Sandra J. Shefelbine ${ }^{4}$ and Janet L. Ronsky ${ }^{5}$
}

\begin{abstract}
Although all functional movement arises from the interplay between the neurological, skeletal, and muscular systems, it is the skeletal system that forms the basic framework for functional movement. Central to understanding human neuromuscular development, along with the genesis of musculoskeletal pathologies, is quantifying how the human skeletal system adapts and mal-adapts to its mechanical environment. Advancing this understanding is hampered by an inability to directly and non-invasively measure in vivo strains, stresses, and forces on bone. Thus, we traditionally have turned to animal models to garner such information. These models enable direct in vivo measures that are not available for human subjects, providing information in regards to both skeletal adaptation and the interplay between the skeletal and muscular systems. Recently, there has been an explosion of new imaging and modeling techniques providing non-invasive, in vivo measures and estimates of skeletal form and function that have long been missing. Combining multiple modalities and techniques has proven to be one of our most valuable resources in enhancing our understanding of the form-function relationship of the human skeletal, muscular, and neurological systems. Thus, to continue advancing our knowledge of the structural-functional relationship, validation of current tools is needed, while development is required to limit the deficiencies in these tools and develop new ones.
\end{abstract}

\section{Background}

Motion in humans and other animals (e.g., walking, running, leaping, flying, and swimming) emerges from the interaction of skeletal shape, strength, and stiffness; musculotendon architecture and mechanics; and neural control. Yet, it is the skeletal system that creates the overall framework for functional movement. The overall shape of bones converts muscle shortening into gross motion; and the specific shape of articular surfaces both guides and constrains motion. Neuromechanical systems, sometimes with surprising self-stabilizing properties, emerge from the interaction of this mechanical complexity with the intricacies of motor and sensory control [1]. Thus, quantifying how the skeletal system adapts and mal-adapts to these stresses is central to understanding neuromuscular development, along with the genesis of musculoskeletal pathologies.

* Correspondence: gavellif@cc.nih.gov

${ }^{1}$ National Institutes of Health, Bethesda, MD, USA

Full list of author information is available at the end of the article
The internal and external geometry of bones and their articular surfaces are the scaffold on which motion is built. Bone geometry varies among individuals and changes substantially during development. It is also influenced by physical activity, injury, and pathology. This geometry is also influenced by evolution. Among the more than 60,000 species of vertebrate animals, skeletal shape varies widely with evolutionary adaptation, such as bat and bird wings for flight and long frog legs for jumping. Discovering robust form-function relationships of the skeletal system in both human and non-human animals is required to advance our understanding of skeletal remodeling, musculoskeletal pathologies, and musculoskeletal function.

New imaging and modeling methods have the potential to advance our knowledge of form-function relationships rapidly. Studies evaluating and models including detailed musculoskeletal morphology, be it patient-specific or species-specific, are an important frontier in the field of biomechanics and neural control of movement. Thus, we need to exploit the tools we currently have at our disposal 
and continue to develop and validate new ones for the accurate and precise quantification of in vivo musculoskeletal properties and the functional movement they enable. The focus of this review is to provide an overview of techniques for advancing understanding of this relationship with specific examples of adaptation and mal-adaptation within the developing skeleton, mature skeleton, musculoskeletal interactions at the joint level, and vertebrates.

\section{The developing skeleton}

It has been known for centuries that altering the load on the bone affects bone development and growth. In ancient China, small feet were a sign of beauty and girls' feet were bound to prevent growth [2]. In Indian and African tribes, the heads of children were bound between planks to elongate the skull, which was considered a sign of nobility [3]. Modern research has confirmed that high loads induce bone formation and reduced loads result in bone resorption, as proposed by Julius Wolff in the 1890s [4]. Growing bone is particularly sensitive to its loading environment because the ossification process can be altered with mechanical loads. This "mechano-sensitivity" allows deformities and dysplasias to develop rapidly when exposed to inappropriate loading. However, it also offers great potential for clinical interventions that obtain appropriate bone loading to ensure normal growth.

Time-varying multi-directional bone loading, resulting from both muscle and external forces, in concert with biochemical factors (e.g., hormones, growth factors, nutrients [5]) directly regulates bone growth. Although the loading environment is complex, it has three key elements: 1) number of loading cycles; 2) magnitude of loading; and 3) direction of loading. The number of loading cycles is the simplest to measure. The direction and magnitude of bone loading are more challenging to assess and typically rely on analysis of motion patterns. Combining motion analysis with musculoskeletal models using inverse kinematics [6], optimization algorithms [7], multi-objective optimization functions [8], or computedmuscle control methods [9] provides estimations of muscle forces, as well as the forces and moments applied to the skeleton. It is these loads that determine the mechanical environment of the growing bone. When musculoskeletal modeling is combined with finite element (FE) bone modeling, tissue-level stresses can be determined. These tissue level stresses, in turn, can be used to predict ossification patterns and ultimately changes to the overall bone shape, such as in developmental dysplasia of the hip $[10,11]$ or bone deformities in cerebral palsy $[12,13]$.

As insightful as these combined motion analysis and modeling approaches have been, understanding the initial skeletal shape is critical to obtaining reliable estimates of joint loads and tissue stresses, particularly when evaluating the pediatric population. This problem becomes even more complicated in the presence of pathology when both bone size and shape can be drastically altered from the typical adult model $[14,15]$. Studies have shown that subject-specific musculoskeletal models estimate significantly reduced joint forces and moments, compared to using scaled generic models [16-18]. For example, estimated joint moments during gait in children with cerebral palsy are reduced when the generic model is replaced with subject-specific morphology [18]. This indicates that the gait in children with cerebral palsy may be "optimized" for the bone shape; or alternatively, the bone shape may be "optimized" for the gait. Likewise, FE models with subject specific growth plate shapes have different tissue stresses than generic growth plate shapes [19]. Thus, taking into account specific geometry is critical in understanding mechanical function.

Another challenge is accurately modeling neuromuscular control parameters for children with altered gait patterns. Currently, musculoskeletal models can predict quite accurately muscle firing patterns and joint loads during typical walking. Yet, children with disabilities (e.g., cerebral palsy, spina bifada) presumably do not use the same optimization criteria in their gait. Mathematically capturing the spasticity, affected neuro-motor control, and muscle tone of these children is challenging. However, these are the populations where altered gait affects bone formation and where the prediction of bone growth is of great clinical interest. Although limitations still remain in measuring or even estimating the loading environment experienced by the pediatric skeletal system, studies combining musculoskeletal and FE modeling have shown that altered loading affects the progression of the growth front and could result in bone deformities [13]. Thus, as our measurement and modeling tools improve, we will have an increased capacity to predict interventional outcomes, streamlining our ability to generate successful patient-specific treatment plans.

While the relationship between form and function is exaggerated in the growing skeleton due to rapid growth, the currents tools have been designed to assess normal adult function. These tools are not adequate for a growing child with bone deformities, yet this is where the clinical need for assessment is highest. Thus, a focused effort is needed to adapt current experimental and modeling techniques to the study of pediatric populations.

\section{The mature skeleton}

After skeletal maturity, bone maintains its capacity to adapt to its mechanical loading environment. This adaptation is driven primarily by strain. Specifically, for a given applied force, weak bones experience larger strains, whereas strong bones experience lower strains. This elicits increased adaptation in the weaker bone, eventually resulting in stronger bone - a phenomenon described by some as a "mechanostat" [20], with bone having a mechanical 
set point, similar to a thermostat. Although the actual process is understood to be more complex than the analogy implies, due to other physiologic factors that influence bone adaptation, the basic principle has been upheld through both retrospective and prospective observation [21-24]. For example, bone adaptation in skeletally mature women has been observed to be site specific and related to energy equivalent strain, with high strain regions experiencing more bone apposition than low strain regions [25].

Although the relationship between mechanical signals and bone adaptation has been extensively studied in animals [26], this relationship is not well understood in humans due to difficulties in noninvasively measuring both the stimulus and the change in bone structure. Thus, mechanical loading in humans is frequently estimated through either retrospective physical activity surveys [27-29] or more directly via measures based on ground reaction force or body segment accelerations [30].These measures are limited in that they do not consider how bone structure, which is highly variable even among healthy individuals, affects bone strain - the driver of bone adaptation. Bone mineral density (BMD) is widely used as a surrogate measure of bone strength. It is inversely related to strain for a given force, but only explains about $50 \%$ of the variance in the relationship [31]. Furthermore, bone strain is highly variable, while BMD is not. For example, in a sample of 23 women with fairly homogenous characteristics, the same simulated external force $(300 \mathrm{~N})$ on the distal radius results in a 6fold variation in mean strains, but only a 2 -fold variation in BMD [32]. Collectively, this indicates that the underlying bone structure is just as important as the density of bone in determining how much strain it will experience for a given force. And, since bone adaptation is strain-driven, it may also partially explain why exercisebased therapies aimed at increasing BMD work for some people, but not others, as exercises are generally prescribed based on force, not bone strain.

In the past decade, three-dimensional imaging methods such as CT and MR imaging have become useful for noninvasively quantifying bone structure, from the micro to the macro scale [33-37]. On the macro-scale, patient-specific CT-based FE models have been shown to accurately estimate bone strain [32, 38, 39] for a variety of physiologic loading scenarios. Not only does CT data provide the basis for patient-specific geometry, these data can account for variations in BMD that are detectable with $\mathrm{x}$-ray, explaining approximately $85 \%$ of the variance in surface strain. The primary limitation to these models is that generally they are validated only in specific loading scenarios and include assumptions and simplifications that limit their application. Furthermore, creating patient-specific FE models is laborintensive. On both the micro- and macroscale, CT data can be analyzed quantitatively to calculate parameters such as bone mineral content and BMD, which have been related to bone tissue elastic modulus [40-43]. High resolution peripheral quantitative CT (HR-pQCT) has rapidly become a method of choice for noninvasive measurement of bone microstructure in living humans. With relatively low radiation exposure (around 3 micro-Sieverts per scan, or roughly half a day's background exposure), HR-pQCT and FE models based on HR-pQCT data have provided useful information regarding specific microstructural changes associated with bone fragility [44]. However, HRpQCT is currently expensive, limited to imaging the extremities, and, practically, it cannot acquire data on more than one or two centimeters of a limb, due to the long scan time and large file sizes associated with very high resolution data.

Bone structure and physical activity are intimately linked, with healthy bones facilitating an active lifestyle and an active lifestyle contributing to healthy bones. The achievement of high peak bone strength during young adulthood imparts lifelong protection against fragility fractures [45]. Subject-specific FE models and microstructural measurements are providing useful insights into how mechanical loads influence bone structure, and how bone structure affects the resulting strain. There is a need for high quality, prospective data linking specific characteristics of mechanical signals and physiologic traits to bone adaptation in healthy and clinical populations. Many challenges exist, such as identifying the threshold between optimal and damaging mechanical loading on both hard and soft tissue, exploiting the natural feedback system to safely strengthen bone in vulnerable populations, and identifying characteristics of people who might respond to such interventions a priori.

\section{Mal-adaptation at the joint level}

As joints enable articulation, healthy musculoskeletal function involves the joint tissues' (e.g., bone, cartilage, tendon, ligaments, etc) ability to continuously adapt their structure and biology to their mechanical loading environment. The specific factors and conditions required to maintain the homeostasis for healthy joint tissues remain poorly understood. Developing techniques to study conditions that result in joint degeneration are shedding light on what is required to maintain healthy joint homeostasis [46-54].

One example of joint degeneration is tibiofemoral osteoarthritis (OA), which severely impacts a patient's quality of life. Treatments to date are limited, with the primary option being pain and inflammation management and, eventually, joint replacement. Many factors, such as trauma, can initiate OA. For example, 12 to 20 year follow ups of athletes who sustained anterior cruciate ligament (ACL) ruptures reveal that $40-50 \%$ of these athletes have OA by ages 25-54 years. Altered joint kinematics and kinetics, associated with ACL 
deficiency (ACLD) [49, 55-59], are theorized to cause a shift in tibiofemoral cartilage contact locations and alter cartilage loading patterns [60]. Such an abrupt injuryinduced change in the joint loading environment may increase cartilage susceptibility to damage at regions illadapted to withstand these altered loads [61-64]. Over years, this interaction causes tissue damage and loss, leading to clinically symptomatic OA. To date, this proposed framework has been difficult to verify directly in humans due to limits in our experimental measurement tools.

Various highly accurate imaging tools can individually provide data in regards to $\mathrm{OA}$, but the true power comes from leveraging these tools off each other. For example, biplanar video-fluoroscopy (BVF) systems, which combine fluoroscopic imaging with magnetic resonance or CT images and use novel calibration approaches, provide the opportunity to obtain submillimeter accuracies in quantifying in vivo 3D bone movements [65-68]. This level of accuracy can likely detect differences between healthy and individuals with ACLD or OA. In addition, during early OA, cartilage exhibits swelling and softening, which can lead to cartilage degeneration [69, 70]. Magnetic resonance imaging of cartilage based on T2 relaxometry has been used to study these early structural and compositional changes, as the sequence is sensitive to collagen architecture, proteoglycan, and water content $[71,72]$. Specifically, higher T2 values have been reported in the tibiofemoral cartilage of individuals with OA and subjects with ACLD [73, 74]. Finally, high resolution magnetic resonance images can provide 3D structural images for deriving bone and cartilage models, along with FE models of cartilage. Combining these tools enables the investigation of in vivo cartilage deformation associated with the bone movement. Quantifying the corresponding $\mathrm{T} 2$ values within contact and non-contact regions for the tibiofemoral cartilage provides information regarding cartilage composition within these regions. Lastly, incorporating measures of muscle activations allows insights into changes in neuro-muscular control associated with the various conditions.

A recent pilot study using this integrated imaging approach, with four healthy and four ACLD individuals, found a substantially higher loading rate under static loading for the ACLD individuals in comparison to the healthy controls [51, 52]. Altered regions of tibiofemoral cartilage contact, as well as altered T2 values in contact and noncontact regions were identified during walking. The average $\mathrm{T} 2$ values for the ACLD limbs were higher than those of the ACL intact limbs, which could be potentially associated with early OA. Thus, applying a combination of tools has provided preliminary evidence on the link between injury, change in cartilage loading, and OA.

Characterizing the relationship between cartilage structure and composition (T2 values) with dynamic loading will likely provide cartilage mechanical function information for early OA detection. The key components involve identifying changes in joint: kinematics and kinetics, morphology, cartilage structure, and neuromuscular control.This integrated structure-function approach provides promise for advancing the understanding of mechanisms of cartilage homeostasis, as well as mal-adaptations, such as cartilage degeneration leading to OA. Further development in 3D-2D registration approaches, numerical simulations and integration of techniques are required to enable these functional dynamic imaging approaches to advance understanding of the in-vivo mechanics of a larger spectrum of healthy joints and those afflicted with pathology.

\section{Skeletal shape and motion across the vertebrates}

As with studies on humans, studies of skeletal shape and motion in non-human animals contribute to our understanding of 3D joint function, to the development of biologically-inspired devices, and to understanding the natural world. Model animal species, such as mice and rats, are developed specifically for biomedical research and benefit from uniformity. At the other extreme, comparative studies of a wide range of species can yield insights beyond what can be learned from direct study of humans and even other mammals. The more than 60,000 species of extant vertebrates exhibit a wide variety of articular surface shapes that guide the motion of joints, permitting some motions and constraining others. But to develop general principles for how articular shape relates to motion, it is necessary to measure both shape and motion simultaneously.

The shape of articular surfaces can be determined with $\mathrm{CT}$ or magnetic resonance imaging and combined with bone motion from BVF to visualize bone shape and motion simultaneously. This combination of techniques has now been applied extensively to study joint function in both humans and other animals [65-67, 75-78]. In most non-human animals, the registration of $3 \mathrm{D}$ bone models to 2D bi-planar video fluoroscopy images can be facilitated by surgical implantation of small $(<1 \mathrm{~mm})$ radiopaque beads into the bones [79]. Combining this motion with a CT scan of the same individual animal yields a precise and accurate (within $\pm 0.1 \mathrm{~mm}$ ) XROMM animation of bone shape and motion $[75,76]$. In most studies of human joints, marker beads cannot be implanted into the bones, so the $3 \mathrm{D}$ to $2 \mathrm{D}$ registration must be done by markerless matching of bone shape data to fluoroscopy images [65-67, 77, 78]. With or without markers, and in humans or other animals, these techniques are yielding unprecedented insights into the relationship between skeletal shape and motion.

For example, using XROMM to study the biomechanics of breathing in lizards is yielding general insights into lung ventilation in all tetrapods, including humans [80], 
as well as specific insights into the similarities, differences, and evolution of ribs and intercostal muscles in various vertebrate groups [81]. Relative to mammals, rib motions for breathing in lizards are exaggerated because lizards lack a diaphragm muscle to assist with lung expansion. Lizards rely entirely on their rib motions for breathing, making them good subjects for deriving general principles for how rib shape and motion interact to expand the thorax [80].

Historical studies on the skeletal form-function relationship in non-human animal models has greatly advanced our understanding of this relationship in humans. A challenge going forward will be to develop the data management tools needed to synthesize skeletal shape and motion data from multiple studies and species. The 3D animations resulting from combining CT or MR imaging data with bi-planar video fluoroscopy are data rich and could be re-analyzed with new methods to answer new questions. But data must be managed and shared in a standardized manner to facilitate sharing and reuse, and this is particularly true for comparative studies among species [82]. Toward developing general principles for how articular shape relates to motion, comparative studies of diverse joints from many species will be necessary for developing statistical models of joint function [83].

\section{Conclusion}

Although all functional movement is born out of the interplay between the neurological, skeletal, and muscular systems, it is the skeletal system that forms the basic framework from which functional movement is created. Not only does it provide the structure to which muscles attach, its shape and size affect the overall ability for a muscle to generate torque, and the skeletal system creates a parameter space for movement. Thus, central to understanding human neuromuscular development, along with the genesis of musculoskeletal pathologies, is an understanding of how the human skeletal system adapts and mal-adapts to its mechanical environment. Advancing this understanding has been hampered by an inability to directly measure the in vivo strains, stresses, and forces on bone, non-invasively in humans. Thus, we have turned to the animal model to evaluate how the skeletal system adapts to long-term stresses through evolution. The animal model also enables direct in vivo measures that are not available in human subjects, providing information in regards to both skeletal adaptation and the interplay between the skeletal and muscular systems. Recently, there has been an explosion of new imaging and modeling techniques that are beginning to provide the in vivo measures of human skeletal form and function that have long been missing. Combining multiple modalities (e.g., a BVF with magnetic resonance image based models, gait analysis with dynamic modeling, CT models with FE models, etc.) has proven to be one of our most valuable resources in enhancing our understanding of the form-function relationship of the human skeletal system, along with the muscular and neurological systems. Many challenges exist in our efforts to fully understand the form-function relationship of the skeletal system, yet progress in the development and validation of tools to measure or estimate skeletal properties has paid high dividends, not only in terms of increased general knowledge, but in the prevention and treatment of various debilitating musculoskeletal impairments and pathologies.

\section{Abbreviations}

ACL: Anterior cruciate ligament; ACLD: ACL deficiency; BVF: Biplanar videofluoroscopy; FE: Finite element; HRpQCT: High resolution peripheral quantitative CT; MR: Magnetic resonance; OA: Osteoarthritis; PF: Proteoglycan; PTOA: Post-traumatic osteoarthritis; TF: Tibiofemoral; XROMM: X-ray reconstruction of moving morphology

\section{Acknowledgments}

This work was funded, in part, by the Intramural Research Program of the National Institutes of Health Clinical Center, Bethesda, MD, USA (author FTS). The authors would like to acknowledge support of the National Science Foundation (grants 1120967, 1262156, 1655756 and 1661129), author ELB; the National Institute for Arthritis and Musculoskeletal and Skin Diseases, NIH, (grant R01AR063691), author KLT; and the Natural Sciences and Engineering Research Council and Alberta Innovates, author JLR. Lastly, we would like to thank the NSF (award CBET 1644835) for financial support in publishing this manuscript.

\section{Funding \\ This work was funded by \\ 1. Intramural Research Program of the National Institutes of Health Clinical Center, Bethesda, MD, USA: author FTS; \\ 2. The National Science Foundation (grants 1120967, 1262156, 1655756 and 1661129):author ELB; \\ 3. The National Institute for Arthritis and Musculoskeletal and Skin Diseases, NIH, (grant R01AR063691): author KLT; \\ 4. The Natural Sciences and Engineering Research Council and Alberta Innovates: author JLR; and \\ 5. NSF award CBET 1644835: Conference and Publication support}

Availability of data and materials

Not applicable.

Authors' contribution

All authors (FTS, ELB, KLT, SJS, and JLR) substantially contributed to the writing of this review article. All authors read and approved the final manuscript.

Ethics approval and consent to participate

Not Applicable.

Consent for publication

Not applicable.

Competing interests

The authors declare that they have no competing interests.

\section{Publisher's Note}

Springer Nature remains neutral with regard to jurisdictional claims in published maps and institutional affiliations. 


\section{Author details}

'National Institutes of Health, Bethesda, MD, USA. ${ }^{2}$ Brown University, Providence, RI, USA. ${ }^{3}$ Worcester Polytechnic Institute, Worcester, MA, USA. ${ }^{4}$ Northeastern University, Boston, MA, USA. ${ }^{5}$ University of Calgary, Calgary, AB, Canada.

Received: 31 May 2017 Accepted: 7 March 2018

Published online: 20 March 2018

\section{References}

1. Nishikawa K, Biewener AA, Aerts P, Ahn AN, Chiel HJ, Daley MA, Daniel TL, Full RJ, Hale ME, Hedrick TL, et al. Neuromechanics: an integrative approach for understanding motor control. Integr Comp Biol. 2007:47:16-54.

2. Ko D. Cinderella's sisters: a revisionist history of Footbinding; 2005. p. 1-332.

3. Tiesler V. Studing cranial vault modifications in ancient Mesoamerica. J Anthropol Sci. 2012;90:33-58.

4. Wolff J. The law of bone remodelling. Berline, New York: Springer-Verlag; 1986.

5. Reddi $\mathrm{AH}$. Cell biology and biochemistry of endochondral bone development. Coll Relat Res. 1981;1:209-26.

6. Erdemir A, McLean S, Herzog W, van den Bogert AJ. Model-based estimation of muscle forces exerted during movements. Clin Biomech. 2007; 22:131-54.

7. Pandy MG. Computer modeling and simulation of human movement. Annu Rev Biomed Eng. 2001;3:245-73.

8. Dumas R, Moissenet F, Lafon Y, Cheze L. Multi-objective optimisation for musculoskeletal modelling: application to a planar elbow model. Proc Inst Mech Eng Part H-J EngMed. 2014;228:1108-13.

9. Thelen DG, Anderson FC. Using computed muscle control to generate forward dynamic simulations of human walking from experimental data. J Biomech. 2006;39:1107-15.

10. Giorgi M, Carriero A, Shefelbine SJ, Nowlan NC. Effects of normal and abnormal loading conditions on morphogenesis of the prenatal hip joint: application to hip dysplasia. J Biomech. 2015;48:3390-7.

11. Shefelbine SJ, Carter DR. Mechanobiological predictions of growth front morphology in developmental hip dysplasia. J Orthop Res. 2004;22:346-52.

12. Shefelbine SJ, Carter DR. Mechanobiological predictions of femoral anteversion in cerebral palsy. Ann Biomed Eng. 2004:32:297-305.

13. Carriero A, Jonkers I, Shefelbine SJ. Mechanobiological prediction of proximal femoral deformities in children with cerebral palsy. Comput Methods Biomech Biomed Engin. 2011;14:253-62.

14. Lenaerts G, De Groote F, Demeulenaere B, Mulier M, Van der Perre G, Spaepen A, Jonkers I. Subject-specific hip geometry affects predicted hip joint contact forces during gait. J Biomech. 2008;41:1243-52.

15. Sheehan FT, Brochard S, Behnam AJ, Alter KE. Three-dimensional humeral morphologic alterations and atrophy associated with obstetrical brachial plexus palsy. J Shoulder Elb Surg. 2014;23:708-19.

16. Wesseling M, De Groote F, Bosmans L, Bartels W, Meyer C, Desloovere K, Jonkers I. Subject-specific geometrical detail rather than cost function formulation affects hip loading calculation. Comput Methods Biomech Biomed Eng. 2016;19:1475-88.

17. Bartels W, Demol J, Gelaude F, Jonkers I, Vander Sloten J. Computed tomography-based joint locations affect calculation of joint moments during gait when compared to scaling approaches. Comput Methods Biomech Biomed Eng. 2015;18:1238-51.

18. Bosmans L, Wesseling M, Desloovere K, Molenaers G, Scheys L, Jonkers I. Hip contact force in presence of aberrant bone geometry during normal and pathological gait. J Orthop Res. 2014;32:1406-15.

19. Yadav P, Shefelbine SJ, Gutierrez-Farewik EM. Effect of growth plate geometry and growth direction on prediction of proximal femoral morphology. J Biomech. 2016;49:1613-9.

20. Frost HM. Bone's mechanostat: a 2003 update. Anat Rec A Discov Mol Cell Evol Biol. 2003;275:1081-101.

21. Karlsson MK. Physical activity, skeletal health and fractures in a long term perspective. J Musculoskelet Neuronal Interact. 2004;4:12-21.

22. Karlsson MK, Magnusson H, Karlsson C, Seeman E. The duration of exercise as a regulator of bone mass. Bone. 2001;28:128-32.

23. Kontulainen $\mathrm{S}$, Sievanen $H$, Kannus $\mathrm{P}$, Pasanen M, Vuori I. Effect of long-term impact-loading on mass, size, and estimated strength of humerus and radius of female racquet-sports players: a peripheral quantitative computed tomography study between young and old starters and controls. J Bone Miner Res. 2003;18:352-9.
24. Troy $\mathrm{KL}$, Edwards WB, Bhatia VA, Bareither ML. In vivo loading model to examine bone adaptation in humans: a pilot study. J Orthop Res. 2013; 31:1406-13

25. Bhatia VA, Edwards WB, Johnson JE, Troy KL. Short-term bone formation is greatest within high strain regions of the human distal radius: a prospective pilot study. J Biomech Eng. 2015:137:1-5.

26. Meakin LB, Price JS, Lanyon LE. The contribution of experimental in vivo models to understanding the mechanisms of adaptation to mechanical loading in bone. Front Endocrinol (Lausanne). 2014;5:154.

27. Bailey CA, Kukuljan S, Daly RM. Effects of lifetime loading history on cortical bone density and its distribution in middle-aged and older men. Bone. 2010;47:673-80

28. Dolan SH, Williams DP, Ainsworth BE, Shaw JM. Development and reproducibility of the bone loading history questionnaire. Med Sci Sports Exerc. 2006:38:1121-31.

29. Kemper HC, Bakker I, Twisk JW, van Mechelen W. Validation of a physical activity questionnaire to measure the effect of mechanical strain on bone mass. Bone. 2002;30:799-804.

30. Turner $\mathrm{CH}$, Robling $\mathrm{AG}$. Designing exercise regimens to increase bone strength. Exerc Sport Sci Rev. 2003;31:45-50.

31. Mancuso ME, Johnson JE, Ahmed SS, Butler TA, Troy KL. Distal radius microstructure and finite element bone strain are related to site-specific mechanical loading and areal bone mineral density in premenopausal women. Bone Reports. (in press)

32. Bhatia VA, Edwards WB, Troy KL. Predicting surface strains at the human distal radius during an in vivo loading task-finite element model validation and application. J Biomech. 2014;47:2759-65.

33. Perilli E, Parkinson $\mathbb{H}$, Reynolds KJ. Micro-CT examination of human bone: from biopsies towards the entire organ. Ann Ist Super Sanita. 2012:48:75-82.

34. Tjong W, Kazakia GJ, Burghardt AJ, Majumdar S. The effect of voxel size on high-resolution peripheral computed tomography measurements of trabecular and cortical bone microstructure. Med Phys. 2012;39:1893-903.

35. Kim DG, Christopherson GT, Dong XN, Fyhrie DP, Yeni YN. The effect of microcomputed tomography scanning and reconstruction voxel size on the accuracy of stereological measurements in human cancellous bone. Bone. 2004;35:1375-82.

36. Muller R, Koller B, Hildebrand T, Laib A, Gianolini S, Ruegsegger P. Resolution dependency of microstructural properties of cancellous bone based on threedimensional mu-tomography. Technol Health Care. 1996:4:113-9.

37. Newitt DC, Majumdar S, van Rietbergen B, von Ingersleben G, Harris ST, Genant HK, Chesnut C, Garnero P, MacDonald B. In vivo assessment of architecture and micro-finite element analysis derived indices of mechanical properties of trabecular bone in the radius. Osteoporos Int. 2002;13:6-17.

38. Edwards WB, Troy KL. Finite element prediction of surface strain and fracture strength at the distal radius. Med Eng Phys. 2012;34:290-8.

39. Schileo E, Taddei F, Malandrino A, Cristofolini L, Viceconti M. Subject-specific finite element models can accurately predict strain levels in long bones. J Biomech. 2007:40:2982-9.

40. Carter DR, Hayes WC. The compressive behavior of bone as a two-phase porous structure. J Bone Joint Surg Am. 1977:59:954-62.

41. Dalstra M, Huiskes R, Odgaard A, van Erning L. Mechanical and textural properties of pelvic trabecular bone. J Biomech. 1993;26:523-35.

42. Morgan EF, Bayraktar HH, Keaveny TM. Trabecular bone modulus-density relationships depend on anatomic site. J Biomech. 2003;36:897-904.

43. Rho JY. Ultrasonic characterisation in determining elastic modulus of trabecular bone material. Med Biol Eng Comput. 1998:36:57-9.

44. Heilmeier U, Cheng K, Pasco C, Parrish R, Nirody J, Patsch JM, Zhang CA, Joseph GB, Burghardt AJ, Schwartz AV, et al. Cortical bone laminar analysis reveals increased midcortical and periosteal porosity in type 2 diabetic postmenopausal women with history of fragility fractures compared to fracture-free diabetics. Osteoporos Int. 2016:27:2791-802.

45. Weaver CM, Gordon CM, Janz KF, Kalkwarf HJ, Lappe JM, Lewis R, O'Karma M, Wallace TC, Zemel BS. The National Osteoporosis Foundation's position statement on peak bone mass development and lifestyle factors: a systematic review and implementation recommendations. Osteoporos Int. 2016;27:1281-386.

46. Behnam AJ, Herzka DA, Sheehan FT. Assessing the accuracy and precision of musculoskeletal motion tracking using cine-PC MRI on a 3.0T platform. J Biomech. 2011;44:193-7.

47. Borotikar BS, Sipprell WH 3rd, Wible EE, Sheehan FT. A methodology to accurately quantify patellofemoral cartilage contact kinematics by 
combining 3D image shape registration and cine-PC MRI velocity data. J Biomech. 2012;45:1117-22.

48. Cuesta-Vargas Al. Development of a new ultrasound-based system for tracking motion of the human lumbar spine: reliability, stability and repeatability during forward bending movement trials. Ultrasound Med Biol. 2015:41:2049-56.

49. Defrate LE, Papannagari R, Gill TJ, Moses JM, Pathare NP, Li G. The 6 degrees of freedom kinematics of the knee after anterior cruciate ligament deficiency: an in vivo imaging analysis. Am J Sports Med. 2006;34:1240-6.

50. Eckstein F, Lemberger B, Stammberger T, Englmeier K, Reiser M. Patellar cartilage deformation in vivo after static versus dynamic loading. J Biomech. 2000;33:819-25.

51. Sharma GB, Beveridge JE, Kuntze G, Bhatla C, Shank J, Ronsky JL. Structural and functional characterization of tibiofemoral cartilage: a dual fluoroscopy and magnetic imaging approach. In: Proc Comp Meth Biomech \& Biomedical Eng \& Imaging \& Visualization; 9/15/2015. Montreal: Springer International Research; 2015.

52. Sharma GB, Kuntze G, Beveridge JE, Bhatla C, Frayne R, Ronsky JL. Subjectspecific 3D T2 relaxation mapping of the tibiofemoral contact regions during walking: a dual fluoroscopy and magnetic resonance imaging approach. In: Orthopaedic Research Society; 2015.

53. Sheehan FT, Smith RM. 3D musculoskeletal kinematics using dynamic MRI. In: Müller B, Wolf SI, Brueggemann G-P, Deng Z, McIntosh A, Miller F, Selbie WS, editors. Handbook of human motion. Cham: Springer International Publishing; 2017. p. 1-17.

54. Smith RM, Sheehan FT. Cross platform comparison of imaging Technologies for Measuring Musculoskeletal Motion. In: Müller B, Wolf SI, Brueggemann G-P, Deng Z, McIntosh A, Miller F, Selbie WS, editors. Handbook of human motion. Cham: Springer International Publishing; 2017. p. 1-22.

55. Benoit DL, Ramsey DK, Lamontagne M, Xu L, Wretenberg P, Renstrom P. In vivo knee kinematics during gait reveals new rotation profiles and smaller translations. Clin Orthop Relat Res. 2007:454:81-8.

56. Tashman S, Collon D, Anderson K, Kolowich P, Anderst W. Abnormal rotational knee motion during running after anterior cruciate ligament reconstruction. Am J Sports Med. 2004;32:975-83.

57. Vergis A, Gillquist J. Sagittal plane translation of the knee during stair walking. Comparison of healthy and anterior cruciate ligament-deficient subjects. Am J Sports Med. 1998:26:841-6.

58. Georgoulis AD, Papadonikolakis A, Papageorgiou CD, Mitsou A, Stergiou N. Three-dimensional tibiofemoral kinematics of the anterior cruciate ligamentdeficient and reconstructed knee during walking. Am J Sports Med. 2003;31:75-9.

59. Andriacchi TP, Dyrby CO. Interactions between kinematics and loading during walking for the normal and ACL deficient knee. J Biomech. 2005;38:293-8.

60. Andriacchi TP, Mundermann A, Smith RL, Alexander EJ, Dyrby CO, Koo S. A framework for the in vivo pathomechanics of osteoarthritis at the knee. Ann Biomed Eng. 2004;32:447-57.

61. Anderst WJ, Tashman S. The association between velocity of the center of closest proximity on subchondral bones and osteoarthritis progression. J Orthop Res. 2009;27:71-7.

62. Maniwa S, Nishikori T, Furukawa S, Kajitani K, Ochi M. Alteration of collagen network and negative charge of articular cartilage surface in the early stage of experimental osteoarthritis. Arch Orthop Trauma Surg. 2001;121:181-5.

63. Akizuki S, Mow VC, Muller F, Pita JC, Howell DS, Manicourt DH. Tensile properties of human knee joint cartilage: I. Influence of ionic conditions, weight bearing, and fibrillation on the tensile modulus. J Orthop Res. 1986; 4:379-92.

64. Chaudhari AM, Briant PL, Bevill SL, Koo S, Andriacchi TP. Knee kinematics, cartilage morphology, and osteoarthritis after ACL injury. Med Sci Sports Exerc. 2008;40:215-22.

65. Sharma GB, Kuntze G, Kukulski D, Ronsky JL. Validating dual fluoroscopy system capabilities for determining in-vivo knee joint soft tissue deformation: a strategy for registration error management. J Biomech. 2015;48:2181-5.

66. Anderst W, Zauel R, Bishop J, Demps E, Tashman S. Validation of threedimensional model-based tibio-femoral tracking during running. Med Eng Phys. 2009;31:10-6.

67. Lichti DD, Sharma GB, Kuntze G, Mund B, Beveridge JE, Ronsky JL. Rigorous geometric self-calibrating bundle adjustment for a dual fluoroscopic imaging system. IEEE Trans Med Imaging. 2015;34:589-98.

68. Miranda DL, Schwartz JB, Loomis AC, Brainerd EL, Fleming BC, Crisco JJ. Static and dynamic error of a biplanar videoradiography system using marker-based and markerless tracking techniques. J Biomech Eng. 2011; 133:121002.

69. Calvo E, Palacios I, Delgado E, Sanchez-Pernaute O, Largo R, Egido J, Herrero-Beaumont G. Histopathological correlation of cartilage swelling detected by magnetic resonance imaging in early experimental osteoarthritis. Osteoarthr Cartil. 2004;12:878-86.

70. Mow VC, Gu WY, Chen FH. Structure and function of articular cartilage and meniscus. In: Mow VC, Huiskes R, editors. Basic orthopaedic biomechanics \& mechano-biology. 3rd ed. Philadelphia, PA: Lippincott Williams \& Wilkins; 2005. p. 181-225.

71. Li X, Cheng J, Lin K, Saadat E, Bolbos RI, Jobke B, Ries MD, Horvai A, Link TM, Majumdar S. Quantitative MRI using T1rho and T2 in human osteoarthritic cartilage specimens: correlation with biochemical measurements and histology. Magn Reson Imaging. 2011;29:324-34.

72. Nishioka H, Hirose J, Nakamura E, Oniki Y, Takada K, Yamashita Y, Mizuta H. T1rho and T2 mapping reveal the in vivo extracellular matrix of articular cartilage. J Magn Reson Imaging. 2012;35:147-55.

73. Klocke NF, Amendola A, Thedens DR, Williams GN, Luty CM, Martin JA, Pedersen DR. Comparison of T1rho, dGEMRIC, and quantitative T2 MRI in preoperative ACL rupture patients. Acad Radiol. 2013;20:99-107.

74. Zarins ZA, Bolbos RI, Pialat JB, Link TM, Li X, Souza RB, Majumdar S. Cartilage and meniscus assessment using T1rho and T2 measurements in healthy subjects and patients with osteoarthritis. Osteoarthr Cartil. 2010;18:1408-16.

75. Brainerd EL, Baier DB, Gatesy SM, Hedrick TL, Metzger KA, Gilbert SL, Crisco JJ. X-ray reconstruction of moving morphology (XROMM): precision, accuracy and applications in comparative biomechanics research. J Exp Zool. 2010;313A:262-79.

76. Knorlein BJ, Baier DB, Gatesy SM, Laurence-Chasen JD, Brainerd EL. Validation of XMALab software for marker-based XROMM. J Exp Biol. 2016; 219:3701-11.

77. Miranda DL, Rainbow MJ, Leventhal EL, Crisco JJ, Fleming BC. Automatic determination of anatomical coordinate systems for three-dimensional bone models of the isolated human knee. J Biomech. 2010;43:1623-6.

78. You BM, Siy P, Anderst W, Tashman S. In vivo measurement of 3-D skeletal kinematics from sequences of biplane radiographs: application to knee kinematics. IEEE Trans Med Imaging. 2001;20:514-25.

79. Tashman S, Anderst W. In-vivo measurement of dynamic joint motion using high speed biplane radiography and $C T$ : application to canine $\mathrm{ACL}$ deficiency. J Biomech Eng. 2003;125:238-45.

80. Brainerd EL. Major transformations in vertebrate breathing mechanisms. In: Dial KP, Shubin N, Brainerd EL, editors. Great transformations in vertebrate evolution. Chicago: Chicago University Press; 2015. p. 47-62.

81. Brainerd EL, Moritz S, Ritter DA. XROMM analysis of rib kinematics during lung ventilation in the green iguana, Iguana iguana. J Exp Biol. 2016;219: 404-11.

82. Brainerd EL, Blob RW, Hedrick TL, Creamer AT, Muller UK. Data management rubric for video data in organismal biology. Integr Comp Biol. 2017;57:33-47.

83. Olsen A, Hernandez P, Camp A, Brainerd E. Linking morphology and motion: testing multibody simulations against in vivo cranial kinematics in suction feeding fishes using XROMM. FASEB J. 2017;31

\section{Submit your next manuscript to BioMed Central and we will help you at every step:}

- We accept pre-submission inquiries

- Our selector tool helps you to find the most relevant journal

- We provide round the clock customer support

- Convenient online submission

- Thorough peer review

- Inclusion in PubMed and all major indexing services

- Maximum visibility for your research

Submit your manuscript at www.biomedcentral.com/submit
Biomed Central 